\title{
Evaluation of Progression Markers in the Premotor Phase of Parkinson's Disease: The Progression Markers in the Premotor Phase Study
}

\author{
Inga Liepelt-Scarfone ${ }^{a, b}$ Katharina Gauss ${ }^{a, b}$ Walter Maetzler ${ }^{a, b}$ \\ Katharina Müller ${ }^{a, b}$ Christian Bormann ${ }^{a, b}$ Monika Fruhmann Berger ${ }^{a, b}$ \\ Maarten Timmers ${ }^{c}$ Johannes Streffer ${ }^{c}$ Daniela Berg ${ }^{a, b}$

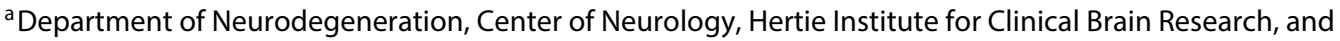 \\ ${ }^{b}$ German Center of Neurodegenerative Diseases, University of Tübingen, Tübingen, Germany; ${ }^{\complement}$ Janssen Research \\ and Development, Janssen, a Pharmaceutical Company of Johnson \& Johnson, Beerse, Belgium
}

\section{Key Words}

Parkinson's disease $\cdot$ Prodromal phase $\cdot$ Progression .

Design · Methodology

\section{Abstract}

Background: The clinical diagnosis of Parkinson's disease (PD) is proposed to be too late for the application of beneficial neuroprotective treatment. Thus, it is important to identify and follow individuals at risk for PD in order to gain knowledge about the prodromal course of the disease. Substantia nigra hyperechogenicity $(\mathrm{SN}+)$ has been confirmed as a risk factor for PD and appears promising as a predictor of $P D$, particularly in combination with other putative PD markers. We present the design and initial data of a 2-year longitudinal investigation of subjects proposed to be at high risk of developing PD ( $\left(\mathrm{HR}_{\mathrm{PD}}\right)$, compared to early PD patients and control subjects. The aim of the presented study is to monitor progression of the neurodegenerative process to motor PD. Methods: In total, $40 \mathrm{HR}_{\mathrm{PD}}, 16 \mathrm{PD}$ and 41 control individuals were recruited. The HRPD subjects had $\mathrm{SN}+$ and additionally either 1 cardinal PD motor sign or 2 further risk (e.g. positive family history) or prodromal markers (e.g. hy- posmia). In this cohort, motor function, olfaction, mood and blood markers will be evaluated every 6 months, complemented by a comprehensive clinical, imaging and electrophysiological assessment. Results: $\mathrm{PD}, \mathrm{HR}_{\mathrm{PD}}$ and control subjects did not differ significantly regarding age, but the $H R_{P D}$ group consisted mainly of males $\left(72.5 \%\right.$ of $\mathrm{HR}_{\mathrm{PD}}$ subjects vs. $43.9 \%$ of controls; $p=0.013$ ). Mean disease duration in PD patients was 31 months (range 15-56). HR $\mathrm{RD}_{\mathrm{PD}}$ subjects were predominantly recruited according to the occurrence of slight motor signs (HRPD 77.5\%, PD 100\%, $p=0.05$; controls $0 \%, H R_{P D}$ vs. controls, $\left.\mathrm{p}<0.017\right)$. The Unified Parkinson's Disease Rating Scale motor score (mean, range) indicated that the HRPD group $(4,0-12)$ had values between those of controls $(0,0-2 ; p<0.017)$ and PD subjects $(26,9-55 ; \mathrm{p}<0.017)$. Among nonmotor symptoms, hyposmia was more common in both $\mathrm{HR}_{\mathrm{PD}}(47.5 \%)$ and $\mathrm{PD}$ subjects $(75 \%)$ than in controls (5.1\%; $p<0.017$ for both comparisons). Conclusions: Here, we describe the recruitment of a highly enriched-risk cohort and a promising study design to assess progression to motor $P D$. Whether the $\mathrm{HR}_{\mathrm{PD}}$ group indeed suffers from early, PDspecific neurodegeneration remains to be verified in the ongoing follow-up examinations.

Copyright $\odot 2013$ S. Karger AG, Basel
KARGER

C 2013 S. Karger AG, Basel

0251-5350/13/0414-0174\$38.00/0 


\section{Introduction}

Parkinson's disease (PD) is a frequent neurodegenerative disorder affecting about $1.8 \%$ of persons older than 55 years [1]. Deposition of $\alpha$-synuclein containing Lewy bodies is the key neuropathologic hallmark of PD, accompanied by striatal loss of dopaminergic neurons. At the time of clinical diagnosis, up to $60 \%$ of dopaminergic neurons in the substantia nigra (SN) have already degenerated [2]. This severe neuronal loss might limit the effect of disease-modifying and neuroprotective therapies [3]. PD thus needs to be diagnosed as early as possible in the neurodegenerative process, at best in its prodromal phase. Importantly, the success of studies investigating novel treatment approaches in the very early phase of PD depends not only on well-characterized risk cohorts but also on markers of progression, which may be used as outcome variables in clinical trials [4].

So far, diagnosis in the prodromal stage of PD, before motor deficits become overt, is limited by the lack of adequate biomarkers $[5,6]$. Most of the clinical markers suggested to antecede PD are not specific for the disease, as they are frequently present in the elderly population or co-occur with other diseases.

Visualization of the presynaptic dopaminergic deficit, for example with single-photon emission computed tomography ( ${ }^{123}$ I-FP-CIT-SPECT), has proven of great value in the diagnosis and differential diagnosis of PD. However, due to the costs, limited availability and exposure to radiation, this method cannot be used as a screening instrument to identify prodromal PD. A promising noninvasive imaging tool to identify individuals at high risk for PD is transcranial sonography (TCS). In the elderly population ( $>50$ years), persons with hyperechogenicity of the $\mathrm{SN}(\mathrm{SN}+)$ assessed by TCS have a 17 - to 20 -fold increased risk of developing PD within 3-5 years [7, 8]. Moreover, $\mathrm{SN}+$ is prominent in more than $90 \%$ of diagnosed PD patients $[9,10]$. Thus, this method is highly sensitive for early PD detection, but its value for predicting PD within a short time period is low $[6,7]$.

Recent work suggests that a combination of $\mathrm{SN}+$ and other preclinical markers may help to identify individuals at high risk for the development of the disease in the near future [11-13]. A higher likelihood for PD has also been shown for multiple- rather than single-marker approaches in the Honolulu-Asia Aging Study (HAAS) and in individuals with idiopathic rapid eye movement sleep behavior disorder (RBD) $[14,15]$.

Markers discussed for the identification of prodromal PD comprise (1) other risk factors such as genetic varia- tions [16, 17], (2) nonmotor markers, i.e. clinical symptoms that are known to precede PD in many cases (e.g. RBD [18], olfactory dysfunction [19]) and (3) early motor signs which indicate that the dopaminergic system is affected (e.g. reduced arm swing on one side, not explained by other deficits) yet are not sufficient for a clinical diagnosis.

Here, we present the design of a prospective, 2-year longitudinal study, devised to investigate subjects presumed to be in the prodromal stage of PD. The aim of the study is to identify (bio)markers or symptoms indicating progression to the early PD stage and therefore allowing for an earlier diagnosis. The strategy used for recruiting individuals at high risk of developing $\mathrm{PD}\left(\mathrm{HR}_{\mathrm{PD}}\right)$ involved choosing subjects with a combination of risk factors and prodromal markers. At subsequent follow-ups, different biomarkers will be evaluated at relatively short time intervals and compared to those in healthy elderly control subjects and PD patients at early stages. Data relating to the study inclusion criteria are also reported in addition to the study design.

\section{Methods}

Study Design

The Progression Markers in the Premotor Phase (PMPP) study is a prospective 2-year longitudinal trial. A population of $40 \mathrm{HR}_{\mathrm{PD}}$ individuals, $16 \mathrm{PD}$ patients in the early disease stage (Hoehn and Yahr stage $<2.5$, see below) and 41 healthy control subjects were recruited. For both $\mathrm{HR}_{\mathrm{PD}}$ and control subjects, the clinical diagnosis of PD was excluded.

\section{Recruitment}

$\mathrm{HR}_{\mathrm{PD}}$ and control subjects were selected according to the criteria reported below, from the well-characterized Prospective Validation of Risk Factors for the Development of Parkinson Syndromes (PRIPS) and Tübinger Evaluation of Risk Factors for the Early Detection of Neurodegeneration (TREND; http://www. trend-studie.de) cohorts $[11,14]$. PD patients were recruited from the outpatient clinic of the Department of Neurodegenerative Diseases, University of Tübingen.

Planned Study Visits

A comprehensive assessment (extended data set) of numerous markers and signs (see below) will be performed yearly. Moreover, subjects in the $\mathrm{PD}$ and $\mathrm{HR}_{\mathrm{PD}}$ groups will be screened for shortterm changes in motor function, olfaction, mood, sleep and medication every 6 months (basic data set, also below). In order to differentiate between PD- and age-related decline, control subjects will be examined twice, namely at baseline and after 2 years (fig. 1).

\section{Inclusion/Exclusion Criteria of Each Study Group}

For inclusion in the $\mathrm{HR}_{\mathrm{PD}}$ group, individuals with $\mathrm{SN}+[11]$ were required to have at least one of the following: (1) 1 PD cardinal motor sign as assessed by the Unified Parkinson's Disease 


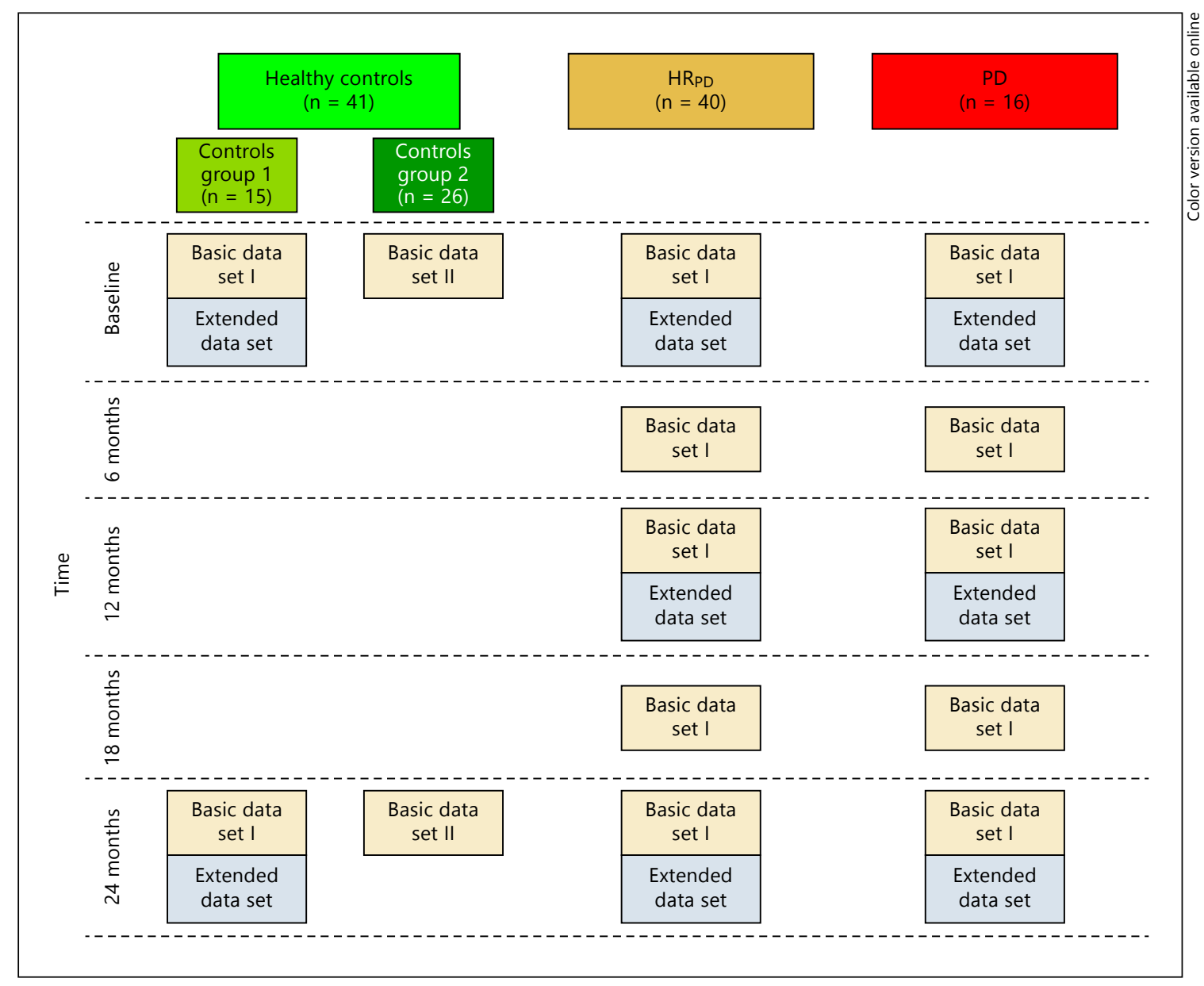

Fig. 1. Overview of the design and follow-up visits of the PMPP study.

Rating Scale (UPDRS)-III motor part [12], or (2) 2 of the following markers - lifetime prevalence of depression [20], hyposmia [21], one-sided reduced arm swing or positive family history of PD [22].

Only individuals with normal echogenicity of the SN [11] (see below), no signs of acute psychiatric diseases and a negative family history of PD [22] were chosen as control subjects. To enable the most efficient collection of data, control subjects were divided into 2 groups, as follows: group 1, consisting of 15 control subjects matched to the PD group with regard to age ( \pm 5 years), gender and education to complete the extended data set investigations, and group 2, consisting of 26 additional control subjects, screened to serve as a validation group for blood markers and questionnaires (table 1).

PD patients in the early disease stages (Hoehn and Yahr stage $\leq 2.5$ ) were diagnosed according to the established diagnostic criteria [23]. They had to be older than 50 years, with no history of deep brain stimulation and no verified genetic mutation known to cause PD.

Exclusion criteria for all participants were as follows: other neurological diseases affecting the central nervous system, history of drug or alcohol abuse, pregnancy, prior use of cholinesterase inhibitors or memantine, or a Mini-Mental State Examination [24] score $\leq 24$ in line with a relevant cognitive deficit indicative of dementia.

\section{Ethical Approval}

The study is being conducted in compliance with the Helsinki Declaration [25]. The study protocol was approved by the local ethical committee of the University of Tübingen. All individuals gave written informed consent.

\section{Assessments at Recruitment}

The following measures were used to verify the above-mentioned inclusion/exclusion criteria. Data from these assessments are reported in the Results section of this paper.

TCS (Antares ${ }^{\circledR}$ ultrasound machine, Siemens, Germany) was performed in all participants to define the echostatus of the SN. A $2.5-\mathrm{MHz}$ transducer was applied. Resolution of this system is approximately as follows: axial $=0.7 \mathrm{~mm}$, lateral $=3 \mathrm{~mm}$. Echogenicity of the SN was measured planimetrically according to the consensus guideline [26]. Based on this guideline and on previous studies $[11,12], \mathrm{SN}+$ was defined as an area of echogenicity greater than or equal to the 90th percentile of a large sample of neuro- 
Table 1. Assessments in the PMPP study

\begin{tabular}{|c|c|c|c|}
\hline \multirow[t]{2}{*}{ Measurement } & \multicolumn{2}{|l|}{ Basic data set } & \multirow{2}{*}{$\begin{array}{l}\text { Extended } \\
\text { data set } \\
\left(\mathrm{PD}, \mathrm{HR}_{\mathrm{PD}}\right. \\
\text { control group 1) }\end{array}$} \\
\hline & $\begin{array}{l}\mathrm{I}: \mathrm{PD}, \mathrm{HR}_{\mathrm{PD}} \\
\text { control group } 1\end{array}$ & $\begin{array}{l}\text { II: control } \\
\text { group } 2\end{array}$ & \\
\hline \multicolumn{4}{|l|}{ Imaging techniques } \\
\hline${ }^{123}$ I-FP-CIT-SPECT & & & + \\
\hline TCS & & + & + \\
\hline MRI & & & + \\
\hline \multicolumn{4}{|l|}{ Electrophysiology } \\
\hline EEG & & & + \\
\hline Ambulatory polysomnography & & & + \\
\hline \multicolumn{4}{|l|}{ Motor assessment } \\
\hline 3D movement analysis (Vicon) & & & + \\
\hline Quantitative ambulatory motor assessment & & & + \\
\hline UPDRS-III & + & + & \\
\hline Hoehn and Yahr Stage & & & + \\
\hline Arm swing & + & + & \\
\hline \multicolumn{4}{|l|}{ Blood sample } \\
\hline DNA, RNA, serum & + & + & \\
\hline \multicolumn{4}{|l|}{ Clinical and demographic data } \\
\hline Medication and concomitant diseases & + & + & \\
\hline Sensory function & & & + \\
\hline Family history of PD & & + & + \\
\hline Edinburgh Handedness Inventory & & & + \\
\hline \multicolumn{4}{|l|}{ Autonomic function } \\
\hline UMSARS Part I, items 9-12 & & & + \\
\hline UMSARS Part III & & & + \\
\hline \multicolumn{4}{|l|}{ Olfaction } \\
\hline 12-Item Sniffin’ Sticks test & + & + & \\
\hline UPSIT & + & & \\
\hline \multicolumn{4}{|l|}{ Depression } \\
\hline Lifetime prevalence & & + & + \\
\hline Major depression & & + & + \\
\hline Beck Depression Inventory & + & + & \\
\hline \multicolumn{4}{|l|}{ Sleep disturbances } \\
\hline Parkinson's Disease Sleep Scale-2 & + & + & \\
\hline RBD screening questionnaire & + & + & \\
\hline \multicolumn{4}{|l|}{ Neuropsychological test battery } \\
\hline Mini-Mental State Examination & + & + & \\
\hline Leistungsprüfsystem 50+ (short version) & & & + \\
\hline Tower of London & & & + \\
\hline Trail-Making Test A and B & & & + \\
\hline Farb-Wort-Interferenz Test (Stroop Test) & & & + \\
\hline California Verbal Learning Test & & & + \\
\hline WMS-R, Logical Memory & & & + \\
\hline WMS-R, Digit Span forward \& backward & & & + \\
\hline HAWIE, Block Design & & & + \\
\hline TAP, Alertness & & & + \\
\hline TAP, Divided Attention & & & + \\
\hline
\end{tabular}

The assessments in the basic data set are applied every 6 months for $\mathrm{PD}, \mathrm{HR}_{\mathrm{PD}}$ and control group 1 subjects and at baseline and after 2 years for control group 2. The assessments in the extended data set are performed yearly. UPSIT = University of Pennsylvania Smell Identification Test; WMS-R = Wechsler Memory Scale, revised; HAWIE = Wechsler Adult Intelligence Scale; TAP = Testbatterie zur Aufmerksamkeitsprüfung. 
degeneratively healthy individuals. Therefore, $\mathrm{SN}$ values above $0.19 \mathrm{~cm}^{2}$ on either the right or left side were defined as $\mathrm{SN}+$. Values equal to or below $0.19 \mathrm{~cm}^{2}$ were rated as $\mathrm{SN}-$. Additionally, the size of the third ventricle, the anterior horn, as well as echogenicity of the raphe, caudate and lentiform nuclei were rated.

Clinical motor assessment was performed by a trained neurologist and included ratings of side differences in arm swing. Slight motor abnormalities possibly indicative for the development of PD were found to be present if the participants showed one of the following signs: slight bradykinesia not due to, for example, an orthopedic cause (any one of the UPDRS-III items $3.4-3.8$ or 3.14 with a score $\geq 1$ ), rigidity (UPDRS-III item 3.3, score $\geq 1$ ) or subtle resting tremor (UPDRS-III items 3.17-3.18, score $\geq 1$ ).

Hyposmia was indicated by a score of below $75 \%$ of correctly identified odors on the Sniffin' Sticks test [21]. Lifetime prevalence and the acute state of depression was diagnosed according to consensus guidelines [20]. A positive family history of PD was defined according to the criteria of Marder et al. [22].

\section{Ongoing Assessments for Measuring Disease Progression}

All assessments applied for recruitment will also be performed in the follow-ups, in addition to the investigations described below (see table 1 and fig. 1 for details regarding the time points of followup).

According to the study design, the total basic data set assessment (approx. $3 \mathrm{~h}$ ) and extended data set assessment (approx. 12$14 \mathrm{~h}$ ) will be conducted on 2 days, between 8 a.m. and 3 p.m. The examination of control subjects who do not receive an ${ }^{123} \mathrm{I}-\mathrm{FP}$ CIT-SPECT (group 1) will be conducted within a day.

\section{Neuroimaging}

All participants who will be assessed yearly with the extended data set $\left(\mathrm{PD}, \mathrm{HR}_{\mathrm{PD}}\right.$ and control subjects of group 1) will receive neuroimaging as long as they do not report any contraindication. This will comprise magnetic resonance imaging (MRI) in addition to TCS. In PD and $\mathrm{HR}_{\mathrm{PD}}$ individuals, investigation with ${ }^{123} \mathrm{I}-\mathrm{FP}$ CIT-SPECT will also be carried out.

Magnetic Resonance Imaging. A comprehensive set of high-resolution images (MAGNETOM Trio, Siemens) will be acquired on a 3-tesla MRI scanner in order to provide information on (1) brain atrophy, vascular diseases and gray matter loss (T1-weighted magnetization-prepared rapid gradient echo sequence), (2) hypointensities in the SN region (T2-weighted multiecho turbo spin echo and $\mathrm{T} 2 *$-weighted multiecho gradient echo), (3) disintegration of white matter fibers (diffusion tensor imaging), (4) dysfunction of the brain perfusion (arterial spin labeling) and (5) metabolic function of the $\mathrm{SN}$ (magnetic resonance spectroscopy).

${ }^{123}$ I-FP-CIT-SPECT. To verify involvement of the nigrostriatal system, the study protocol includes ${ }^{123} \mathrm{I}$-FP-CIT-SPECT (DaTSCAN ${ }^{\mathrm{TM}}$ ), which has proven to be useful not only for PD diagnosis but also in the early (prodromal) and differential diagnosis of PD [27]. Participants will receive a single intravenous injection of ${ }^{123}$ I-FP-CIT (GE Healthcare, Zeist, The Netherlands) at the recommended dose of $185 \mathrm{MBq}$. Three hours following the injection, SPECT images will be acquired with a dual-head gamma camera high-resolution collimator (Symbia ${ }^{\circledR}$, Siemens). The acquisition time will be approximately $40 \mathrm{~min}$. Data analysis will focus on the location and amount of both striatal and extrastriatal tracer uptake.
Electroencephalography and Polysomnography

Several studies have demonstrated that idiopathic RBD may increase the risk of future PD significantly [28-30]. RBD is characterized by loss of normal skeletal muscle atonia during rapid eye movement sleep, such that patients move in apparent response to their dream content. The standard procedure for RBD diagnosis is the use of polysomnography [31]. For this study, an ambulatory sleep stage evaluation system (SOMNOscreen ${ }^{\mathrm{TM}}$ plus, SOMNOmedics $\mathrm{GmbH}$, Germany) will be used to enable sleep recording in the participant's normal sleeping environment at home. Moreover, abnormal electroencephalography (EEG) activities characterized by diffuse and/or localized slowing have been observed in PD. These shifts in the EEG pattern seem to be related to nonmotor rather than motor signs, i.e. to symptoms known to precede PD [32-34]. During this study, EEG recording using a standard IS 10-20 system ( $5 \mathrm{~min}$ in the resting condition with eyes open and closed, each for $30 \mathrm{~s}, 5$ times in a row) will be applied.

\section{Motor Assessment}

Motor impairment is the core feature of clinical PD. Importantly, a specific subclinical movement profile is supposed to predict future PD-related motor worsening. Motor assessment will include the UPDRS-III, the Hoehn and Yahr scale [35] and quantitative measurements. Those quantitative assessments allow for a detailed characterization of even slight variations in movement patterns and have been validated to depict a $\mathrm{PD}$-specific motor profile [36].

We will register individual 3-dimensional movement trajectories using a Vicon 612 motion capture system (sampling rate 120 $\mathrm{Hz}$ ) with 8 infrared cameras and 41 reflecting markers on anatomical landmarks. Additionally, quantitative axial movement data will be recorded with a wearable inertial sensor (sampling rate 100 $\mathrm{Hz}$; DynaPort Hybrid, McRoberts, The Hague, Netherlands) fixed with an elastic belt at the level of the third and fourth lumbar spine segment, close to the center of mass [37]. For each participant, different movement tasks (e.g. finger or foot tapping, gait, sway) known to indicate changes in the early stages of PD will be assessed $[36,38,39]$.

\section{Laboratory Tests}

Blood samples will be taken at every study visit. Sampling protocols have been fitted to collect DNA and RNA for genomic and functional genomic analyses, as well as serum and plasma for metabolomics and proteomics.

Assessment of Nonmotor Symptoms

Parts of the Unified Multiple System Atrophy Rating Scale (UMSARS) will be used to assess autonomic function [40]. Examination of orthostatic dysregulation will be based on the UMSARSIII. The UMSARS-I items 9-12 account for the patient's historical review of orthostatic symptoms and urinary, sexual and bowel function.

The German version of the University of Pennsylvania Smell Identification Test will serve as the measurement to define progression of olfactory dysfunction, in addition to the 12-item Sniffin' Sticks test. Subjects with actual or chronic diseases that might reduce olfactory performance (e.g. chronic rhinitis) will be excluded from data analysis. The revised version of the Parkinson's Disease Sleep Scale [41] and the RBD Screening Questionnaire [42] will be used to assess self-perceived sleep problems and evidence 
Table 2. Characterization of study groups

\begin{tabular}{|c|c|c|c|c|c|c|}
\hline Variable & Control group 1 & Control group 2 & $\begin{array}{l}\text { All control } \\
\text { subjects }\end{array}$ & $\mathrm{HR}_{\mathrm{PD}}$ & PD & $\mathrm{p}$ value \\
\hline Number & 15 & 26 & 41 & 40 & 16 & \\
\hline Age, years & $63(54-76)$ & $59(50-71)$ & $60(50-76)$ & $62(45-73)$ & $64(50-80)$ & 0.28 \\
\hline Male, $\mathrm{n}$ & $7(46.7)$ & $11(42.3)$ & $18(43.9)$ & $29(72.5)$ & $9(56.3)$ & $0.04^{1}$ \\
\hline \multicolumn{7}{|l|}{ Risk factors for PD } \\
\hline $\mathrm{SN}+, \mathrm{n}$ & $0(0)$ & $0(0)$ & $0(0)$ & $40(100)$ & $15(93.3)$ & $<0.001^{1,2}$ \\
\hline \multicolumn{7}{|l|}{ Nonmotor symptoms } \\
\hline Hyposmia, $\mathrm{n}$ & $1(7.7)$ & $1(3.8)$ & $2(5.1)$ & $19(47.5)$ & $12(75)$ & $<0.001^{1,2}$ \\
\hline Lifetime prevalence of depression, $\mathrm{n}$ & $2(13.3)$ & $0(0)$ & $2(4.9)$ & $13(32.5)$ & $8(50)$ & $<0.001^{1,2}$ \\
\hline \multicolumn{7}{|l|}{ Early motor signs } \\
\hline One-sided reduced arm swing, $\mathrm{n}$ & $0(0)$ & $0(0)$ & $0(0)$ & $15(37.5)$ & $14(87.5)$ & $<0.001^{1-3}$ \\
\hline Cardinal sign of $\mathrm{PD}, \mathrm{n}$ & $0(0)$ & $0(0)$ & $0(0)$ & $31(77.5)$ & $16(100)$ & $<0.001^{1,2}$ \\
\hline
\end{tabular}

Figures in parentheses represent ranges or percentages, as appropriate. $\mathrm{p}$ values refer to comparison of all control subjects, $\mathrm{HR}_{\mathrm{PD}}$ and PD patients (Kruskal-Wallis test). For the analysis of motor impairment (cardinal sign of PD, UPDRS-III total score) one subject of the control group was excluded due to orthopedic reason.

Post hoc comparison: $\mathrm{p}<0.017$ :

${ }^{1} \mathrm{HR}_{\mathrm{PD}}$ group vs. all control subjects.

${ }^{2}$ PD patients vs. all control subjects.

${ }^{3} \mathrm{PD}$ patients vs. $\mathrm{HR}_{\mathrm{PD}}$ group.

of RBD. The Beck Depression Inventory [43] will be applied to give insight into the course of depressive symptoms during the study period. A comprehensive neuropsychological test battery (table 1) has been composed which will cover all major areas of potential cognitive disability known to be affected in early $\mathrm{PD}[35,44]$.

Data Analysis and Statistics

Longitudinal data analyses will include prevalence, risk and incidence estimates of PD and other neurodegenerative disorders, descriptive statistics and multivariate analysis (regression models, latent growth mixture models, analysis of variance, structural equation models) to account for disease progression. Cross-sectional (sub)group comparisons (e.g. demographics) will be conducted - depending on the data type - with either parametric ( $t$ test, analysis of variance) or nonparametric statistics (e.g. Kruskal-Wallis $\mathrm{H}$ test).

Results of the presented group characteristics were based on descriptive and nonparametric test statistics (Mann-Whitney test for 2 samples and Kruskal-Wallis test for 3 samples). The data were analyzed using IBM SPSS Statistics 20.0 for Windows.

\section{Results}

The subjects recruited consisted of $16 \mathrm{PD}, 40 \mathrm{HR}_{\mathrm{PD}}$ and 41 control subjects. Mean disease duration in $\mathrm{PD}$ patients was 31 months (range 15-56). Six PD patients received dopamine agonists, 1 patient was medicated with rasagi- line only, 2 patients took a combination of levodopa, carbidopa and entacapone, 2 patients were medicated with a dopamine agonist and a catechol-o-methyltransferase inhibitor and 5 took both levodopa and dopamine agonists ( 1 of them additionally received amantadine and 1 a catechol-o-methyltransferase inhibitor). Antidepressant medication was more common in the $\mathrm{PD}$ than in the $\mathrm{HR}_{\mathrm{PD}}$ group (31.3 vs. $12.5 \% ; \mathrm{p}=0.03$ ). One $\mathrm{PD}$ patient was treated with quetiapine because of previous manic-depressive episodes. She never received typical neuroleptics. Healthy control subjects received none of these drugs.

The control groups $1(n=15)$ and $2(n=26)$ did not differ significantly with regard to demographical or clinical recruitment parameters $(p>0.05)$. The first statistical analyses were thus carried out with regard to the data of the whole control group $(\mathrm{n}=41$; table 2$)$.

$\mathrm{PD}, \mathrm{HR}_{\mathrm{PD}}$ and control subjects did not differ significantly regarding age, but the $\mathrm{HR}_{\mathrm{PD}}$ group consisted of mainly males ( $72.5 \%$ of $\mathrm{HR}_{\mathrm{PD}}$ subjects vs. $43.9 \%$ of controls; $\mathrm{p}=0.013)$. More than two thirds $(\mathrm{n}=31,77.5 \%)$ of the $\mathrm{HR}_{\mathrm{PD}}$ group showed slight motor signs, predominantly mild forms of bradykinesia (72.5\%).

Among the nonmotor symptoms, hyposmia (47.5\%) was the most common sign in both $\mathrm{PD}$ and $\mathrm{HR}_{\mathrm{PD}}$ individuals. In addition, 19 subjects $\left(\mathrm{PD}=31.3 \%, \mathrm{HR}_{\mathrm{PD}}=\right.$ 
$35.0 \%)$ reported a first-degree relative, 7 subjects $(\mathrm{PD}=$ $\left.18.8 \%, \mathrm{HR}_{\mathrm{PD}}=10 \%\right)$ a second-degree relative and $4 \mathrm{pa}-$ tients $\left(\mathrm{PD}=18.8 \%, \mathrm{HR}_{\mathrm{PD}}=2.5 \%\right)$ other family relatives with PD symptoms.

\section{Discussion}

The PMPP study was designed to investigate the progression of various biomarkers in the prodromal phase of PD. To the best of our knowledge, this is the first study designed to comprehensively assess individuals at high risk for idiopathic PD at short (6-month) intervals.

Most symptoms that hallmark the prodromal stage of $\mathrm{PD}$ are unspecific when they are evaluated alone, but their co-occurrence in an individual is proposed to increase the risk for PD and (in the case of a neurodegenerative process) correspond to the neuropathological staging of PDassociated Lewy body pathology [45-47]. We therefore recruited individuals showing not only one marker but a combination of various risk and prodromal markers.

Based on our study design, the clinical profile of the $\mathrm{HR}_{\mathrm{PD}}$ group partly resembles that of $\mathrm{PD}$ patients and differs from controls in various aspects. This finding supports the assumption that the recruitment of an $\mathrm{HR}_{\mathrm{PD}}$ cohort is feasible.

So far, little is known about the prevalence, co-occurrence and progression of prodromal markers before the clinical symptoms enable PD diagnosis. Therefore, studies which follow the early development of PD are urgently needed, such as the study presented here. As discussed below, our approach differs from that of other ongoing prospective longitudinal studies.

Large population-based longitudinal cohort studies such as the HAAS [19] or PRIPS study [7] focus on risk factors or prodromal markers, to specify their predictive value for future $\mathrm{PD}$. One main advantage is that the diagnostic value of a marker, or a combination of markers, can be specified in the general population. However, assessments used in these studies need to be quickly and easily applied and thus may not allow a detailed quantification of various signs and symptoms.

Given that the incidence of PD is only about 0.3 per 1,000 persons in subjects aged 55-65 years [48], population-based cohorts are not a primary target in pharmacological trials. Therefore, a large number of participants must be examined in order to identify those who will develop PD in the near future.

The investigation of 'enriched-risk cohorts' seems to be a promising approach, as a larger number of individu- als are supposed to develop PD. The TREND study selected 12,000 persons older than 50 years of age with the presence of idiopathic hyposmia, depression and self-reported signs of RBD or none of these markers (control subjects). Participants are assessed every 2 years with a 3.5-hour quantitative assessment battery, including motor, olfactory, autonomic, visual and cognitive function, as well as TCS [14].

Another example of an 'enriched-risk cohort' is the Parkinson At-Risk Syndrome Study (PARS). In this study, 9,398 individuals older than 50 years of age without neurodegenerative disorders were screened via mail, using the University of Pennsylvania Smell Identification Test [49]. Olfactory function could be analyzed in 4,999 subjects, of whom 669 (13.4\%) were classified as having hyposmia. In the PARS study design, individuals from this hyposmic group undergo additional assessments.

In all these studies (HAAS, PRIPS, TREND, PARS), the primary outcome is the development of $\mathrm{PD}$ according to the current diagnostic criteria [23]. Follow-up intervals are generally 2 or even more years apart, to enable the best effort/cost and outcome relation in these large cohorts [14]. However, such periods are far too long to monitor possible effects in pharmacological trials testing new drugs which aim to modulate the neurodegenerative process [4]. Here, a different approach is needed, which we propose in the PMPP study.

In contrast to the PMPP study, the Parkinson's Progression Markers Initiative [50], a multicenter (23 PD centers: 14 across the USA, 4 in Europe) observational research study, is designed to identify biomarkers of early PD progression. However, the present PMPP study does not focus on the characterization of disease progression in early neurodegenerative stages, but rather is designed to address the prodromal stage.

There are some limitations in the present design that were unavoidable at this stage. Due to ethical reasons, healthy control subjects will not receive ${ }^{123}$ I-FP-CITSPECT imaging. Therefore, this part of the assessment will provide information about changes in tracer uptake in $\mathrm{HR}_{\mathrm{PD}}$ and early $\mathrm{PD}$ patients over time, but we will not be able to correct for age-related changes of the dopaminergic system. A further limitation of the present study is the rather small sample size.

However, we believe that this explorative and small study is a feasible, highly competitive and promising approach to develop relevant trait and state markers for the prodromal phase of PD. Data analysis of the PMPP study has the potential to serve as a relevant basis for the conception of future studies in this area. 


\section{Acknowledgements}

The authors thank all participants and all staff members.

The PMPP study is being funded by an unrestricted grant from Janssen Research and Development (Belgium), a pharmaceutical company of Johnson \& Johnson.

\section{Disclosure Statement}

Johannes Streffer and Maarten Timmers are employed by Johnson \& Johnson, which sponsored the PMPP study. The funding of the PMPP study is precompetitive.

\section{References}

1 de Rijk MC, Launer LJ, Berger K, Breteler MM, Dartigues JF, Baldereschi M, Fratiglioni L, Lobo A, Martinez-Lage J, Trenkwalder C, Hofman A: Prevalence of Parkinson's disease in Europe: a collaborative study of population-based cohorts. Neurologic Diseases in the Elderly Research Group. Neurology 2000; 54(11 suppl 5):S21-S23.

-2 Fearnley JM, Lees AJ: Ageing and Parkinson's disease: substantia nigra regional selectivity. Brain 1991;114:2283-2301.

3 Olanow CW, Obeso JA: The significance of defining preclinical or prodromal Parkinson's disease. Mov Disord 2012;27:666-669.

-4 Streffer JR, Grachev ID, Fitzer-Attas C, Gomez-Mancilla B, Boroojerdi B, Bronzova J, Ostrowitzki S, Victor SJ, Fontoura P, Alexander R: Prerequisites to launch neuroprotective trials in Parkinson's disease: an industry perspective. Mov Disord 2012;27: 651-655.

5 Siderowf A, Lang AE: Premotor Parkinson's disease: concepts and definitions. Mov Disord 2012;27:608-616.

6 Lang AE: A critical appraisal of the premotor symptoms of Parkinson's disease: potential usefulness in early diagnosis and design of neuroprotective trials. Mov Disord 2011;26: 775-783.

$>7$ Berg D, Seppi K, Behnke S, Liepelt I, Schweitzer $\mathrm{K}$, Stockner $\mathrm{H}$, Wollenweber $\mathrm{F}$, Gaenslen A, Mahlknecht P, Spiegel J, Godau J, Huber H, Srulijes K, Kiechl S, Bentele M, Gasperi A, Schubert T, Hiry T, Probst M, Schneider V, Klenk J, Sawires M, Willeit J, Maetzler W, Fassbender K, Gasser T, Poewe $\mathrm{W}$ : Enlarged substantia nigra hyperechogenicity and risk for Parkinson disease: a 37-month 3-center study of 1847 older persons. Arch Neurol 2011;68:932-937.

$\checkmark 8$ Berg D, Behnke S, Seppi K, Godau J, Lerche S, Mahlknecht P, Liepelt-Scarfone I, Pausch C, Schneider N, Gaenslen A, Brockmann K, Srulijes K, Huber H, Wurster I, Stockner H, Kiechl S, Willeit J, Gasperi A, Fassbender K, Gasser T, Poewe W: Enlarged hyperechogenic substantia nigra as a risk marker for Parkinson's disease. Mov Disord 2012;28: 216-219.

-9 Berg D, Jabs B, Merschdorf U, Beckmann H, Becker G: Echogenicity of substantia nigra determined by transcranial ultrasound correlates with severity of parkinsonian symptoms induced by neuroleptic therapy. Biol Psychiatry 2001;50:463-467.
10 Walter U, Behnke S, Eyding J, Niehaus L, Postert T, Seidel G, Berg D: Transcranial brain parenchyma sonography in movement disorders: state of the art. Ultrasound Med Biol 2007;33:15-25.

11 Berg D, Seppi K, Liepelt I, Schweitzer K, Wollenweber F, Wolf B, Dillmann U, Stockner $H_{\text {, }}$ Godau J, Kiechl S, Gaenslen A, Willeit J, Di Santo A, Maetzler W, Gasser T, Poewe W, Behnke S: Enlarged hyperechogenic substantia nigra is related to motor performance and olfaction in the elderly. Mov Disord 2010;25: 1464-1469.

12 Liepelt I, Behnke S, Schweitzer K, Wolf B, Godau J, Wollenweber F, Dillmann U, Gaenslen A, Di Santo A, Maetzler W, Berg D: Pre-motor signs of PD are related to SN hyperechogenicity assessed by TCS in an elderly population. Neurobiol Aging 2011;32: 1599-1606.

13 Ruprecht-Dorfler P, Klotz P, Becker G, Berg D: Substantia nigra hyperechogenicity correlates with subtle motor dysfunction in tap dancers. Parkinsonism Relat Disord 2007;13: 362-364.

14 Berg D, Marek K, Ross GW, Poewe W: Defining at-risk populations for Parkinson's disease: lessons from ongoing studies. Mov Disord 2012;27:656-665.

15 Postuma RB, Gagnon JF, Vendette M, Desjardins C, Montplaisir JY: Olfaction and color vision identify impending neurodegeneration in rapid eye movement sleep behavior disorder. Ann Neurol 2011;69:811-818.

16 Siderowf A, Jennings D, Connolly J, Doty RL, Marek K, Stern MB: Risk factors for Parkinson's disease and impaired olfaction in relatives of patients with Parkinson's disease. Mov Disord 2007;22:2249-2255.

17 Mizuno Y, Hattori N, Kubo S, Sato S, Nishioka $\mathrm{K}$, Hatano T, Tomiyama H, Funayama M, Machida Y, Mochizuki H: Progress in the pathogenesis and genetics of Parkinson's disease. Philos Trans R Soc Lond B Biol Sci 2008; 363:2215-2227.

18 Postuma RB, Gagnon JF, Rompre S, Montplaisir JY: Severity of REM atonia loss in idiopathic REM sleep behavior disorder predicts Parkinson disease. Neurology 2010;74:239244.

19 Ross GW, Petrovitch H, Abbott RD, Tanner CM, Popper J, Masaki K, Launer L, White LR: Association of olfactory dysfunction with risk for future Parkinson's disease. Ann Neurol 2008;63:167-173.
20 The ICD-10 Classification of Mental and Behavioural Disorders: Clinical Descriptions and Diagnostic Guidelines. Geneva, World Health Organization, 1992.

21 Hummel T, Konnerth CG, Rosenheim K, Kobal G: Screening of olfactory function with a four-minute odor identification test: reliability, normative data, and investigations in patients with olfactory loss. Ann Otol Rhinol Laryngol 2001;110:976-981.

-22 Marder K, Tang MX, Mejia H, Alfaro B, Cote L, Louis E, Groves J, Mayeux R: Risk of Parkinson's disease among first-degree relatives: a community-based study. Neurology 1996; 47:155-160.

23 Hughes AJ, Daniel SE, Lees AJ: The clinical features of Parkinson's disease in 100 histologically proven cases. Adv Neurol 1993;60:595-599.

24 Folstein MF, Folstein SE, McHugh PR: 'Minimental state'. A practical method for grading the cognitive state of patients for the clinician. J Psychiatr Res 1975;12:189-198.

25 World Medical Association declaration of Helsinki. Recommendations guiding physicians in biomedical research involving human subjects. JAMA 1997;277:925-926.

26 Berg D, Behnke S, Walter U: Application of transcranial sonography in extrapyramidal disorders: updated recommendations. Ultraschall Med 2006;27:12-19.

27 Brooks DJ: Imaging dopamine transporters in Parkinson's disease. Biomark Med 2010;4: 651-660.

28 Schenck CH, Bundlie SR, Mahowald MW: Delayed emergence of a parkinsonian disorder in $38 \%$ of 29 older men initially diagnosed with idiopathic rapid eye movement sleep behaviour disorder. Neurology 1996;46:388-393.

29 Postuma RB, Gagnon JF, Vendette M, Fantini ML, Massicotte-Marquez J, Montplaisir J: Quantifying the risk of neurodegenerative disease in idiopathic REM sleep behavior disorder. Neurology 2009;72:1296-1300.

30 Iranzo A, Molinuevo JL, Santamaria J, Serradell M, Marti MJ, Valldeoriola F, Tolosa E: Rapid-eye-movement sleep behaviour disorder as an early marker for a neurodegenerative disorder: a descriptive study. Lancet Neurol 2006;5:572-577.

31 Boeve BF: REM sleep behavior disorder: updated review of the core features, the REM sleep behavior disorder-neurodegenerative disease association, evolving concepts, controversies, and future directions. Ann NY Acad Sci 2010;1184:15-54. 
-32 Morita A, Kamei S, Serizawa K, Mizutani T: The relationship between slowing EEGs and the progression of Parkinson's disease. J Clin Neurophysiol 2009;26:426-429.

-33 Serizawa K, Kamei S, Morita A, Hara M, Mizutani T, Yoshihashi H, Yamaguchi $M$, Takeshita J, Hirayanagi K: Comparison of quantitative EEGs between Parkinson disease and age-adjusted normal controls. J Clin Neurophysiol 2008;25:361-366.

34 Bonanni L, Thomas A, Tiraboschi P, Perfetti $B$, Varanese S, Onofrj M: EEG comparisons in early Alzheimer's disease, dementia with Lewy bodies and Parkinson's disease with dementia patients with a 2-year follow-up. Brain 2008;131:690-705.

35 Dubois B, Burn D, Goetz C, Aarsland D, Brown RG, Broe GA, Dickson D, Duyckaerts C, Cummings J, Gauthier S, Korczyn A, Lees A, Levy R, Litvan I, Mizuno Y, McKeith IG, Olanow CW, Poewe W, Sampaio C, Tolosa E, Emre M: Diagnostic procedures for Parkinson's disease dementia: recommendations from the movement disorder society task force. Mov Disord 2007;22:2314-2324.

- 36 Brewer BR, Pradhan S, Carvell G, Delitto A: Feature selection for classification based on fine motor signs of Parkinson's disease. Conf Proc IEEE Eng Med Biol Soc 2009;2009:214217.

-37 Moe-Nilssen R: Test-retest reliability of trunk accelerometry during standing and walking. Arch Phys Med Rehabil 1998;79: 1377-1385.

-38 Mancini M, Carlson-Kuhta P, Zampieri C, Nutt JG, Chiari L, Horak FB: Postural sway as a marker of progression in Parkinson's disease: a pilot longitudinal study. Gait Posture 2012;36:471-476.
39 Lewek MD, Poole R, Johnson J, Halawa O, Huang X: Arm swing magnitude and asymmetry during gait in the early stages of Parkinson's disease. Gait Posture 2010;31:256-260.

40 Wenning GK, Tison F, Seppi K, Sampaio C, Diem A, Yekhlef F, Ghorayeb I, Ory F, Galitzky M, Scaravilli T, Bozi M, Colosimo C, Gilman S, Shults CW, Quinn NP, Rascol O, Poewe W: Development and validation of the Unified Multiple System Atrophy Rating Scale (UMSARS). Mov Disord 2004;19:1391-1402.

41 Trenkwalder C, Kohnen R, Hogl B, Metta V, Sixel-Doring F, Frauscher B, Hulsmann J, Martinez-Martin P, Chaudhuri KR: Parkinson's disease sleep scale - validation of the revised version PDSS-2. Mov Disord 2011;26: 644-652.

42 Stiasny-Kolster K, Mayer G, Schafer S, Moller JC, Heinzel-Gutenbrunner M, Oertel WH: The REM sleep behavior disorder screening questionnaire - a new diagnostic instrument. Mov Disord 2007;22:2386-2393.

43 Hautzinger M, Bailer M, Worall H, Keller F: Becks-Depressions-Inventar (BDI). Bern, Huber, 1995.

44 Muslimovic D, Post B, Speelman JD, Schmand $B$ : Cognitive profile of patients with newly diagnosed Parkinson disease. Neurology 2005; 65:1239-1245.

45 Braak H, Del Tredici K, Rub U, de Vos RA, Jansen Steur EN, Braak E: Staging of brain pathology related to sporadic Parkinson's disease. Neurobiol Aging 2003;24:197-211.

-46 Przuntek H, Muller T, Riederer P: Diagnostic staging of Parkinson's disease: conceptual aspects. J Neural Transm 2004;111:201-216.
47 Gaenslen A, Swid I, Liepelt-Scarfone I, Godau J, Berg D: The patients' perception of prodromal symptoms before the initial diagnosis of Parkinson's disease. Mov Disord 2011;26: 653-658.

48 de Lau LM, Giesbergen PC, de Rijk MC, Hofman A, Koudstaal PJ, Breteler MM: Incidence of parkinsonism and Parkinson disease in a general population: the Rotterdam Study. Neurology 2004;63:1240-1244.

49 Siderowf A, Jennings D, Eberly S, Oakes D, Hawkins KA, Ascherio A, Stern MB, Marek $\mathrm{K}$ : Impaired olfaction and other prodromal features in the Parkinson At-Risk Syndrome Study. Mov Disord 2012;27:406-412.

50 Marek K, Jennings D, Lasch S, Siderowf A, Tanner C, Simuni T, Coffey C, Kieburtz K, Flagg E, Chowdhury S, Poewe W, Mollenhauer B, Sherer T, Frasier M, Meunier C, Rudolph A, Casaceli C, Seibyl J, Mendick S, Schuff N, Zhang Y, Toga A, Crawford K, Ansbach A, De Blasio P, Piovella M, Trojanowski J, Shaw L, Singleton A, Hawkins K, Eberling J, Brooks D, Russell D, Leary L, Factor S, Sommerfeld B, Hogarth P, Pighetti E, Williams K, Standaert D, Guthrie S, Hauser R, Delgado H, Jankovic J, Hunter C, Stern M, Tran B, Leverenz J, Baca M, Frank S, Thomas CA, Richard I, Deeley C, Rees L, Sprenger F, Lang E, Shill H, Obradov S, Fernandez H, Winters A, Berg D, Gauss K, Galasko D, Fontaine D, Mari Z, Gerstenhaber M, Brooks D, Malloy S, Barone P, Longo K, Comery T, Ravina B, Grachev I, Gallagher K, Collins M, Widnell KL, Ostrowizki S, Fontoura P, La-Roche F, Ho T, Luthman J, van der Brug M, Reith AD, Taylor P; the Parkinson Progression Marker Initiative: The Parkinson Progression Marker Initiative (PPMI). Prog Neurobiol 2011;95:629-635. 